\title{
PYRIDOXINE-DEPENDENT CONVULSIONS IN AN INFANT
}

\author{
BY \\ R. GARTY, Z. YONIS, J. BRAHAM and K. STEINITZ \\ From Beilinson Hospital, Petah Tikva, Israel
}

(RECEIVED FOR PUBLICATION JULY 21, 1961)

The association of dietary pyridoxine deficiency and convulsions was first noted in animal experiments by Chick, El Sadr and Worden (1940). An analogous situation in humans was recognized when Snyderman, Carretero and Holt (1950) described the onset of seizures in a mentally retarded child whose diet lacked this vitamin. Shortly afterwards, an outbreak of convulsions in young infants in the United States was shown to be due to the low pyridoxine content in their diet (Coursin, 1954; Molony, 1954; Bessey, Adam, Bussey and Hansen, 1954; Adam, Bessey, Bussey and Hansen, 1954; May, 1954). An association of a different category was first recorded when Hunt, Stokes, McCrory and Stroud (1954) described the case of an infant who began to suffer from seizures a few hours after birth. Pyridoxine in high doses abolished the attacks, and the term 'pyridoxine dependency' was used to describe this situation in which convulsions are of early onset and dietary deficiency cannot be invoked. Only three other reports have been encountered (Bessey, Adam and Hansen, 1957; Marie, Hennequet, Lyon, Debris and Le Balle, 1959; Scriver, 1960) describing infants whose attacks similarly responded to pyridoxine therapy.

The case reported here seems to fulfil the criteria for its acceptance as a further instance of convulsions associated with a state of pyridoxine dependency.

\section{Case Report}

A female infant born of Iraqi Jewish parents, was admitted six hours after birth, because of severe generalized convulsions. The father was healthy; the mother was known to suffer from aortic valvular disease and nephrolithiasis. There had been 10 pregnancies, the fourth, sixth and eighth terminating in spontaneous abortion in the first and second trimesters. Two infants, one male, one female, born at term following normal pregnancies (the seventh and ninth) died between the ages of 1 and 3 months, after repeated convulsions which first appeared shortly after birth.

The present pregnancy and delivery were normal, the infant breathed spontaneously and weighed $2,800 \mathrm{~g}$. Generalized convulsions had been present almost continuously for two hours in spite of parenteral barbiturates and chloral hydrate. She was cyanotic except for brief periods of respite, the slightest touch or noise provoking a short tonic spasm with cyanosis and apnoea. No abnormalities were detected on physical examination.

Investigations. Lumbar puncture revealed a clear cerebrospinal fluid, containing 3 cells; protein $140 \mathrm{mg}$./ $100 \mathrm{ml}$., sugar $67 \mathrm{mg} . / 100 \mathrm{ml}$. Subdural needling was dry. Sabin-Feldman test, Wassermann and Nelson tests, in the infant and her parents, were negative. Blood chemistry revealed calcium $10 \mathrm{mg} .100 \mathrm{ml}$, phosphorus $6 \mathrm{mg} . / 100 \mathrm{ml}$, alkaline phosphatase 10 Bodansky units, fasting sugar $82 \mathrm{mg} . / 100 \mathrm{ml}$., urea $24 \mathrm{mg} . / 100 \mathrm{ml}$., sodium $140 \mathrm{mEq} / \mathrm{litre}$; chloride 99 $\mathrm{mEq} /$ litre; $\mathrm{CO}_{2}$-combining power $52 \%$; total protein $5.5 \mathrm{~g} . / 100 \mathrm{ml}$, albumin $3.31 \mathrm{~g} . / 100 \mathrm{ml}$., electrophoresis of blood proteins normal. Liver tests normal. Transaminase (glutamic-oxalacetic) 55 units. Haemoglobin $18 \mathrm{~g} . / 100 \mathrm{ml}$., erythrocytes $5,400,000$, leucocytes and differential count normal. Chromatography of amino acids in urine normal. Ferric chloride test negative. Radiographs of skull revealed no calcifications or other abnormalities.

Electroencephalogram was abnormal and showed periodic groups of medium to high voltage generalized beta and theta waves with occasional spikes. These bursts lasted from two to five seconds, and alternated in an irregular fashion with periods of very fast waves of extremely low voltage, almost amounting to electrical silence (Fig. 1). Pneumoencephalography performed later during hospitalization showed signs of slight cortical atrophy.

Seizures continued to recur at irregular intervals up to four to five times daily and were uninfluenced by barbiturates or phenytoin. Feeding was difficult because of the convulsions, and, in spite of the use of a gastric tube, aspiration pneumonia supervened with right upper lobe atelectasis. This complication responded to antibiotics. No aetiological factor having been detected and, there being a lack of response to anticonvulsants, it was decided to try pyridoxine treatment.

On the eleventh day, during a severe attack, $5 \mathrm{mg}$. were injected intramuscularly. Within 15 minutes the convulsions ceased; the infant became lethargic, unresponsive and flaccid, with shallow breathing. This state lasted some 36 hours after which, following a period of increasing restlessness with short tonic responses to 


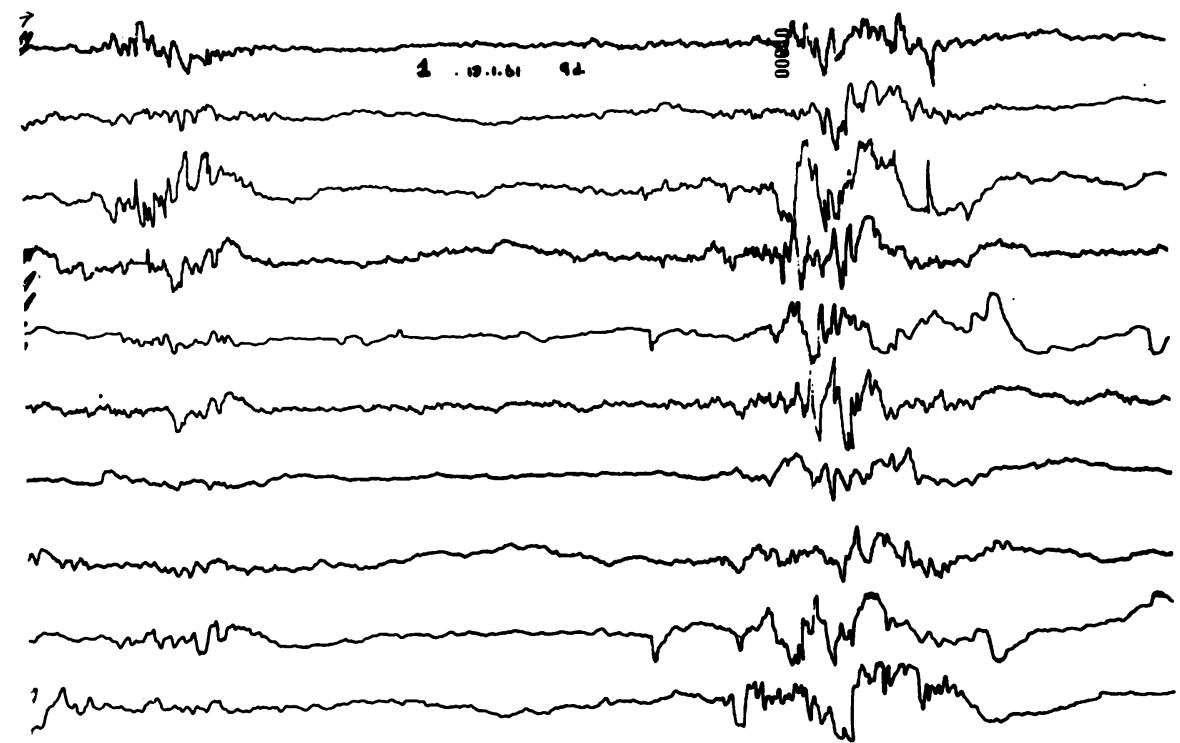

FIG. 1.-E.E.G. tracing at the age of 9 days, showing generalized high-voltage irregular sharp and slow wave burst supervening on period of relative electrical silence.

stimuli, severe generalized convulsions reappeared. Remission lasting some 36 hours was again obtained after pyridoxine injection, until seizures recurred and were once more abolished by pyridoxine injection. This sequence of events repeated on three occasions seemed to offer conclusive evidence, and the infant was then maintained on an oral daily dose of $7.5 \mathrm{mg}$. of the vitamin. Seizures remained in abeyance and the general condition rapidly improved with satisfactory weight gain.

The electroencephalogram at this stage was normal, showing a diffuse irregular background with no paroxysmal features (Fig. 2). The daily dosage was gradually reduced to $2.5 \mathrm{mg}$. with no untoward effect.

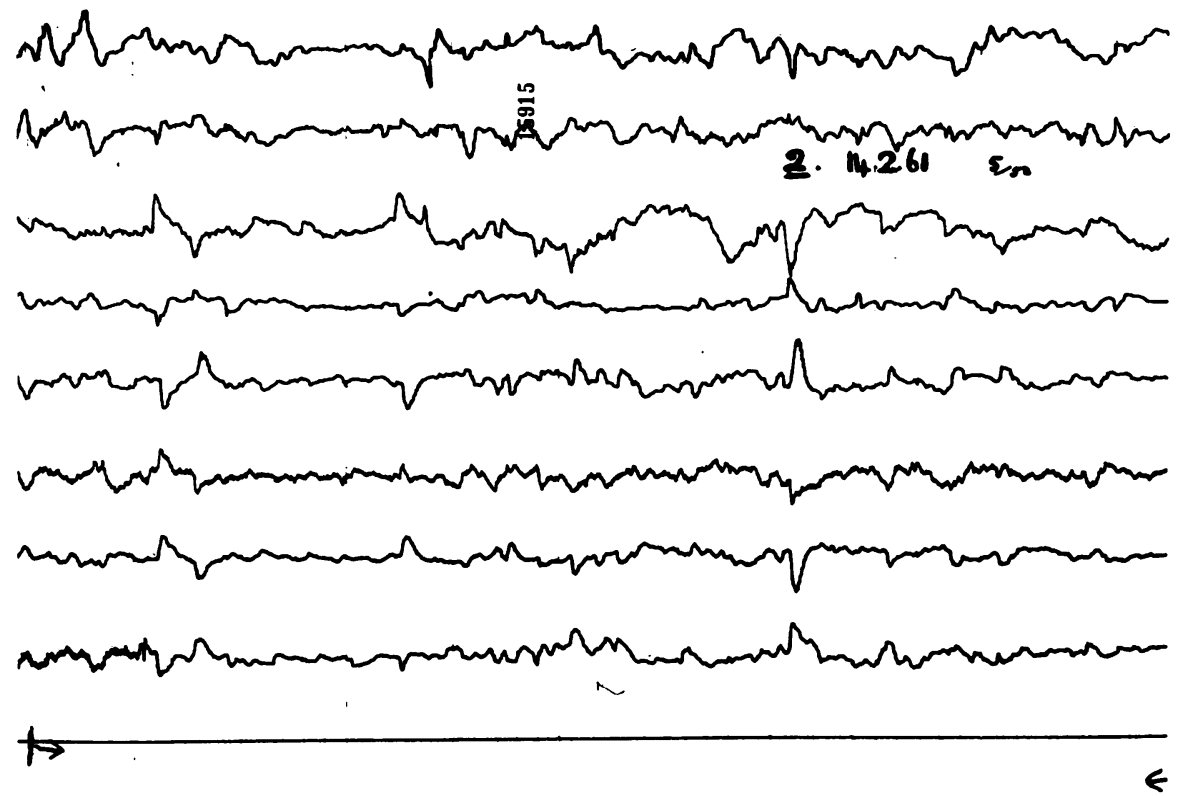

FIG. 2.-Tracing at the age of 5 weeks, three weeks after beginning pyridoxine treatment. 
On the 58th day, therapy was interrupted in order to perform a tryptophane-loading test. There was no xanthurenic acid in the urine after a tryptophane load of $0.54 \mathrm{~g} . / \mathrm{kg}$. body weight. Severe convulsions recurred 48 hours later, and the electroencephalogram was once again abnormal, with periods of high voltage activity made up of mixed slow and fast frequencies and numerous sharp waves. These episodes lasted from seconds to a minute or two and again were interspersed with passages of sudden complete cessation of electrical activity. Convulsions were almost constant except in the electrically silent periods (Fig. 3). Parenteral barbiturates were ineffective and cessation of convulsions followed within 10 minutes of injection of $2.5 \mathrm{mg}$. pyridoxine. The electroencephalogram was normal the next day (Fig. 4). The infant is now on a maintenance dose of $2 \mathrm{mg}$. pyridoxine. During a trial to reduce the daily dose to $1 \mathrm{mg}$., she was restless and irritable.

\section{Discussion}

The exact mechanism responsible for the appearance of convulsions in states of pyridoxine deficiency and dependency is not known. Pyridoxal coenzyme, one of the forms in which vitamin $\mathbf{B}_{6}$ occurs in foods and body fluids, is required for the intermediary metabolism of amino acids (Snell, 1953; 1958). Increased urinary excretion of xanthurenic acid after tryptophane loading is one of the meta-

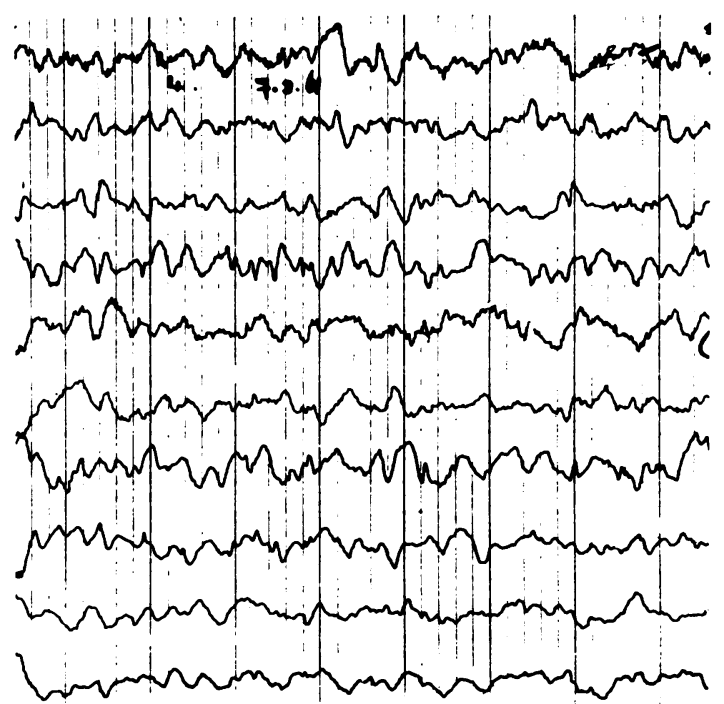

FIG. 4.-Tracing taken the day after that of Fig. 3, and 24 hours after recommencement of treatment.

bolic defects noted in pyridoxine deficiency (Snyderman et al., 1950; Bessey et al., 1957; Rabe and Plonko, 1956) or when a pyridoxine antagonist is

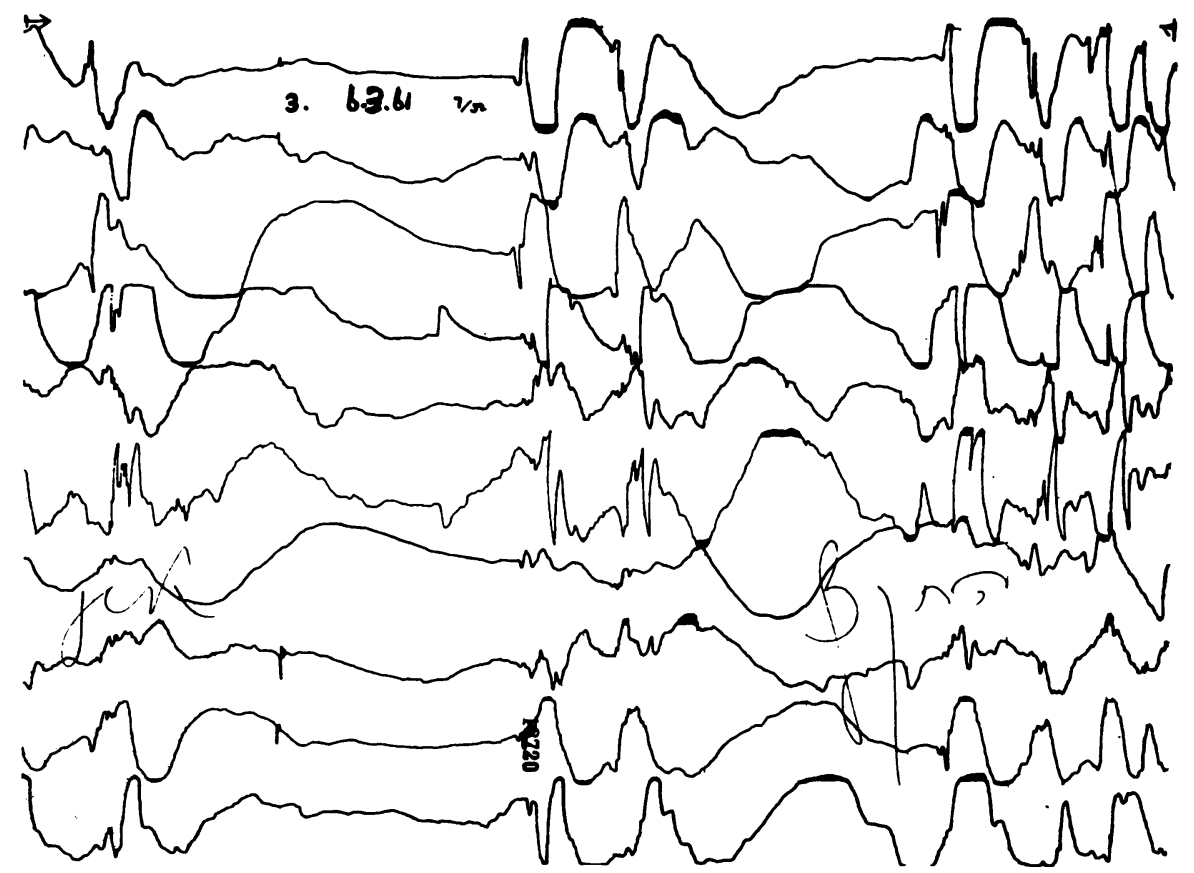

FIG. 3.-Tracing 36 hours after interruption of therapy, showing burst alternating irregularly with silent periods. 
administered (Mueller and Vilter, 1950; Biehl and Vilter, 1954; Price, Brown and Larson, 1957). This aberration of tryptophane metabolism cannot be considered responsible for the appearance of convulsions; moreover, it is not found in states of pyridoxine dependency. The convulsions in both deficiency and dependency states are due to the derangement of other enzymatic systems in which the vitamin serves as a coenzyme. Serotonin and gamma aminobutyric acid (GABA), known to be concerned with normal brain function, require the presence of pyridoxal coenzyme for their conversion from 5-hydroxytryptophane and glutamic acid, respectively. The GABA system is believed to be involved primarily in the convulsions of vitamin $B_{6}$ dependency and deficiency. GABA, which probably participates in oxidative processes in brain (Sokoloff, Lasson, McKhann, Tower and Albers, 1959), was found to be reduced in brains of rats given toxopyrimidine, an antagonist of pyridoxine (Rindi and Ferrari, 1959).

In the states of deficiency, small doses of pyridoxine, almost equivalent to the normal daily requirement, are needed to suppress the convulsions, whereas in the states of dependency, much higher doses are required (Coursin, 1955). Absorptive defect being excluded, and excessive renal loss of vitamin $\mathbf{B}_{6}$ being unlikely to affect the availability of pyridoxal coenzyme in the states of dependency, an abnormality of the apoenzyme system of the brain, with increased demand for the coenzyme was postulated by Scriver (1960). The early onset of convulsions and the continuous high dosage of pyridoxine required to abolish them in our patient preclude pyridoxine deficiency. Hunt et al. (1954) suggested that the state of 'dependency' could be related to a high prenatal maternal intake of the vitamin, but no vitamin supplements had been administered during this pregnancy. For this reason a genetic enzymatic abnormality of the infant's brain metabolism seems likely. This may well have been the case in the two siblings who died of convulsions.

\section{Summary}

A case is presented in which severe generalized seizures, unresponsive to routine anticonvulsant therapy, began a few hours after birth. No cause for the seizures was discovered, but treatment with pyridoxine resulted in their cessation. The convulsions recurred 36 to 48 hours after withdrawal of therapy. This is believed to be the fifth reported publication of pyridoxine-dependent convulsions.

Two untreated siblings died with the same symptoms. The cause of the disorder is believed to be genetic enzymatic abnormality of the brain.

\section{REFERENCES}

Adam, D. J. D., Bessey, O. A., Bussey, D. R. and Hansen, A. E. (1954). Vitamin $\mathrm{B}_{6}$ requirement in relation to convulsive seizures in infants. Amer. J. Dis. Child., 88, 623.

Bessey, O. A., Adam, D. J. D., Bussey, D. R. and Hansen, A. E. (1954). Vitamin $\mathbf{B}_{6}$ requirements in infants. Fed. Proc., 13, 451 .

and Hansen, A. E. (1957). Intake of vitamin $\mathbf{B}_{6}$ and infantile convulsions: a first approximation of requirements of pyridoxine in infants. Pediatrics, 20, 33

Biehl, J. P. and Vilter, P. W. (1954). Effects of isoniazid on pyridoxine metabolism. J. Amer. med. Ass., 156, 1549.

Chick, H., El Sadr, M. M. and Worden, A. M. (1940). Occurrence of fits of an epileptiform nature in rats maintained for long periods on a diet deprived of vitamin $B_{6}$. Biochem. J., 34, 595.

Coursin, D. B. (1954). Convulsive seizures in infants with pyridoxine-deficient diet. J. Amer. med. Ass., 154, 406.

(1955). Vitamin $\mathbf{B}_{6}$ deficiency in infants: a follow-up study. Amer. J. Dis. Child., $90,344$.

Hunt, A. D., Stokes, J., McCrory, W. W. and Stroud, H. H. (1954). Pyridoxine dependency; a report of a case of intractable convulsions in an infant controlled by pyridoxine. Pediatrics, $13,140$. Marie, J., Hennequet, A., Lyon, G., Debris, J. and Le Balle, J. C.
(1959). Les crises convulsives pyridoxino-sensibles du nouveauné et du nourrisson. Sem. Hôp. Paris, 35, 1411. (Ann. Pédiat., 5, p. 197.)

May, C. D. (1954). Vitamin $B_{6}$ in human nutrition: a critique and an object lesson. Pediatrics, 14, 269.

Molony, C. J. (1954). Convulsions in young infants as a result of pyridoxine (vitamin $\mathrm{B}_{6}$ ) deficiency. J. Amer. med. Ass., 154, 405.

Mueller, J. E. and Vilter, R. W. (1950). Pyridoxine deficiency in human beings induced with desoxypyridoxine. J. clin. Invest., 29, 193.

Price, J. M., Brown, R. R. and Larson, F. C. (1957). Quantitative studies on human urinary metabolites of tryptophan as affected by isoniazid and deoxypyridoxine. ibid., 36, 1600.

Rabe, E. and Plonko, M. (1956). Pyridoxine hydrochloride (vitamin $B_{6}$ ) need in infants and children: a study in patients with anemia, $B_{6}$ ) need in infants and children: a study in patients with anem.

convulsions and acute infections. Amer. J. Dis. Child., 92, 38 .
Rindi, G. and Ferrari, G. (1959). The gamma-aminobutyric acid and glutamic acid content of brains of rats treated with Toxopyrimidine. Nature (Lond.), 183, 608.

Scriver, Ch. R. (1960). Vitamin $B_{6}$-dependency and infantile convulsions. Pediatrics, 26, 62.

Snell, E. E. (1953). Summary of known metabolic functions of nicotinic acid, riboflavin and vitamin $\mathbf{B}_{6}$. Physiol. Rev., 33, 509 .

(1958). Chemical structure in relation to biological activities of vitamin $\mathbf{B}_{6}$. Vitam. and Horm., 16, 77.

Snyderman, S. E., Carretero, R. and Holt, L. E., Jr. (1950). Pyridoxine deficiency in the human being. Fed. Proc., 9, 371.

Sokoloff, L., Lasson, M. A., McKhann, G. M., Tower, D. B. and Albers, W. (1959). Effects of pyridoxine withdrawal on cerebral circulation and metabolism in a pyridoxine-dependent child. Nature (Lond.), 183, 751. 